\title{
Robotic cardiac surgery: current status and future directions
}

This article was published in the following Dove Press journal:

Robotic Surgery: Research and Reviews

24 October 2014

Number of times this article has been viewed

\author{
Emmanuel Moss \\ Douglas A Murphy \\ Michael E Halkos \\ Division of Cardiothoracic Surgery, \\ Emory University School of \\ Medicine, Atlanta, GA, USA
}

Correspondence: Emmanuel Moss 5665 Peachtree Dunwoody Rd NE, Atlanta, GA 30342, USA

$\mathrm{Tel}+\mathrm{I} 4047787200$

Fax + I 4046864959

Email emmanuel.moss@emory.edu
Abstract: Since robotic cardiac surgery was first described nearly 2 decades ago, technological advance along with a growing demand for less invasive procedures have given way to increased development and adoption of robot-assisted cardiac surgery. Coronary revascularization is now being performed with varying degrees of robotic assistance. Robot-assisted single vessel and hybrid coronary artery revascularization is gaining popularity, and multivessel totally endoscopic coronary artery bypass surgery is being performed safely in select highly specialized centers. Intracardiac robot-assisted surgery has also become an attractive alternative to midline sternotomy and thoracoscopic approaches for mitral and tricuspid valve disease, atrial septal defect repair, and intracardiac tumors. This review will describe the current state of robotic cardiac surgery and offer some insight into future advancement.

Keywords: robot-assisted, mitral valve, coronary artery bypass, minimally invasive surgery

\section{Introduction}

The theoretical advantages of minimally invasive cardiac surgery have been well described, and favorable reports continue to surface in the literature. In addition to smaller incisions and improved cosmesis, patients may benefit from shorter intensive care unit (ICU) and hospital stays, and an earlier return to their preoperative functional level. Although robot-assisted cardiac surgery was first described nearly 2 decades ago, ${ }^{1,2}$ recent technological advances occurring concurrently with the growing demand for less invasive procedures have given way to the development and more widespread implementation of robotic telemanipulation platforms to facilitate the performance of minimally invasive cardiac surgery. These advancements include higher definition three-dimensional scopes, thinner and longer instruments, and a third robotic arm that allows for the addition of an endostabilizer to use for coronary bypass surgery or a left atrial retractor for intracardiac surgery. The da Vinci Surgical System (Intuitive Surgical, Sunnyvale, CA, USA) is currently the only robotic surgical system approved by the United States Food and Drug Administration (FDA) for cardiac surgery. When used concomitantly with techniques, perfusion systems, and myocardial protection strategies that have been developed to facilitate minimal access surgery, robotic technology demonstrates obvious advantages over traditional video-assisted thoracoscopic surgery. Its three-dimensional high definition capabilities and articulating wrists allow a greater freedom of movement in an enclosed space compared with traditional longshafted instruments. The da Vinci system allows articulating instruments to move with six degrees of freedom, rather than four degrees with long-shafted instruments, and eliminates the surgeon's tremor, if present. Robotic technology has now been 
shown safe and feasible, being routinely used in specialized centers to perform surgeries of varying levels of complexity, including coronary surgery, mitral and tricuspid valve surgery, atrial fibrillation ablations, cardiac tumor resections, and congenital heart operations. In addition to the technical advantages of robot-assisted surgery, the body of literature supporting equivalent or improved perioperative outcomes is steadily growing. Authors have found advantages over traditional surgery with regard to decreased transfusion requirements, decreased hospital length of stay, and faster return to preoperative functional levels when compared with sternotomy. Future iterations of the robotic telemanipulation system may introduce haptic technology and facilitate even further its use for complex cardiac surgery. This review will describe the current state of robotic cardiac surgery and offer some perspectives for future advancement.

\section{Coronary revascularization}

The surgical treatment of coronary artery disease (CAD) has evolved significantly over the last several decades, with regard to both conduits and the introduction of less invasive approaches. Since Loop et $\mathrm{al}^{3}$ reported a significant survival benefit grafting the left internal mammary artery (LIMA) to the left anterior descending artery (LAD), it has become the gold standard in surgical revascularization. ${ }^{3,4}$ This has caused surgeons to focus on this conduit-vessel combination and has led to the development of minimal access techniques for LIMA harvest and anastomosis to the LAD. This began with minimally invasive direct coronary artery bypass (MIDCAB) procedures with LIMA harvesting and LIMA-LAD anastomosis performed through a left anterior thoracotomy in the fourth or fifth intercostal space..$^{5-9}$ Surgeons skilled in endoscopy applied these techniques to LIMA harvest and successfully performed EndoACAB (endoscopic atraumatic coronary artery bypass graft [CABG]) procedures. ${ }^{7,10}$ The technique allows complete LIMA harvest to be performed via small thoracoscopic incisions without the significant upward chest wall retraction that is required with MIDCAB. The LIMA-LAD anastomosis can then be performed through a small anterior minithoracotomy. Although this procedure can be performed safely and with good results in experienced hands, its broad adoption has been hindered by the long learning curve of the thoracoscopic harvest.

\section{Robot-assisted LIMA harvest}

Robot-assisted LIMA harvest with a hand-sewn LIMA-LAD anastomosis offers the same advantages as EndoACAB, but the shorter learning curve using the da Vinci system has per- mitted more widespread implementation of the approach. It can generally be performed with three 8-10 $\mathrm{mm}$ incisions followed by a 3-4 cm anterior minithoracotomy without using a rib spreader. Pericardiotomy and target vessel localization are accomplished prior to the thoracotomy, facilitating a smaller incision directly over the target vessel. While our institution has previously published excellent results with EndoACAB, we have evolved to perform the robot-assisted CABG technique exclusively because we believe it provides the optimal mix of practicality, patient benefit, "teachability," and operating room efficiency. ${ }^{5,10,11}$ We recently published our institution's series of 307 patients who underwent robot-assisted CABG surgery, with a low 30-day mortality (1.3\%), low rates of conversion to sternotomy (5.2\%), perioperative myocardial infarction (1.6\%), and postoperative stroke $(0.3 \%)$, and a $97 \%$ graft patency when including patients that underwent intraoperative graft revisions. ${ }^{12-14}$ Nesher et $\mathrm{al}^{15}$ published a series of 146 consecutive robot-assisted CABGs without any in-hospital deaths and $96.3 \%$ patency rate. ${ }^{15}$ A more recent study by Currie et $\mathrm{al}^{1}$ reported $93.4 \%$ patency at a mean of 96 months follow-up in 82 patients who underwent robotassisted CABG. ${ }^{1,2}$ The study also evaluated quality of life and demonstrated an overall positive effect; however, the report lacked a comparison with standard $\mathrm{CABG}$.

\section{Robot-assisted TECAB}

Some surgeons have transitioned to robot-assisted totally endoscopic coronary artery bypass (TECAB). The first TECAB operation was performed in 1999 on an arrested heart utilizing femoral arterial and venous cannulation and intra-aortic balloon occlusion. ${ }^{3,4}$ Subsequent reports evolved toward an off-pump beating-heart technique with an anastomosis that can be performed using monofilament suture or anastomotic devices. ${ }^{5-9}$ The first larger series was reported by Mohr et $\mathrm{al}^{7}$ in 2001, describing 27 patients who underwent LIMA harvest and LIMA to LAD anastomosis using the da Vinci telemanipulation system. ${ }^{7,10}$ In 2006, a multicenter FDA-sanctioned trial demonstrated the safety and efficacy of TECAB using the da Vinci system in 85 patients..$^{5,10,11}$ There were no deaths or strokes during the follow-up period, and 91\% freedom from reintervention or angiographic stenosis of greater than $50 \%$. Although many authors have shown singlevessel TECAB to be technically feasible, with an overall improvement in quality of life compared with conventional $\mathrm{CABG}$, there is a significant learning curve that results in prolonged operative times and possibly increased complication rates early in a surgeon's experience. ${ }^{12-14}$ Despite overall good short-term results, the aforementioned shortcomings 
and minimal perceived advantages over single-vessel robotic MIDCAB has limited its widespread adoption.

Multivessel TECAB is the least invasive but most complex method of non-sternotomy revascularization. Beatingheart surgery, either off-pump or pump-assisted, is facilitated by using the endostabilizer that attaches to the fourth arm on the da Vinci robot, available on newer generation machines. Although an off-pump approach is feasible for LAD and diagonal vessel targets, exposing and grafting lateral and inferior wall territories is technically demanding and requires cardiopulmonary bypass (CPB) with or without cardioplegic arrest. Bonatti et al have championed multivessel TECAB and are responsible for a significant number of publications on the subject. His group recently published their series of 500 totally endoscopic CABGs, including 166 multivessel TECABs. ${ }^{16}$ The report assessed "success" and "safety" of the procedure, stating rates of $80 \%$ and $95 \%$, respectively. In an earlier publication, the same group analyzed their long-term results with multivessel TECAB specifically. ${ }^{17}$ The majority of these cases were two-vessel CABGs, with $11.7 \%$ being three-vessel TECABs, and one patient $(0.5 \%)$ underwent four-vessel TECAB. This group has previously reported operative times averaging 225 minutes for singlevessel TECAB, and in this publication they report an average just over 6 hours for multivessel TECAB. Conversion rate was $17 \%$, with acceptable rates of typical perioperative complications. Five-year survival and freedom from major adverse cardiac and cerebrovascular events were $96 \%$ and $73 \%$, respectively. The authors also reported an average return to full physical activity of 42 days, which is significantly lower than the 8-12 weeks of sternal precautions that are typically recommended following sternotomy. Srivastava et $\mathrm{al}^{18}$ reported their series of 164 consecutive beating-heart TECABs, which included 73 multivessel CABGs. In-hospital mortality and complication rates were low. Early graft patency was $99.5 \%$ as assessed by either computed tomography angiography or conventional angiography.

It is clear that robotic TECAB is a technically challenging operation with a long learning curve and a high risk of complications due to technical difficulties. While most publications would suggest that the procedure can be performed safely and effectively, one must remember that learning curves are slow and operative times are long, even in the most experienced hands. The controversy lies in understanding whether patient safety and long-term outcomes are being compromised to accommodate this complex minimally invasive procedure. Wiedemann et al ${ }^{19}$ demonstrated that operative times longer than 478 minutes are associated with intraoperative technical difficulties and increased perioperative morbidity. Another study suggested that TECAB may increase postoperative morbidity and mortality compared with Society of Thoracic Surgeons National Database expected outcomes. These concerns, along with the previously stated long learning curve make widespread adoption of this technique unlikely at this time.

\section{Hybrid coronary revascularization}

Fueled by the demand for less invasive procedures, good outcomes with minimally invasive $\mathrm{CABG}$, mediocre outcomes with saphenous vein grafts, and improved results with percutaneous coronary intervention (PCI) using drug eluting stents, hybrid coronary revascularization (HCR) has attracted significant interest in recent years from both surgeons and cardiologists. Although many techniques have been described, robotic assistance is ideally suited for combining the sternal sparing surgical LAD revascularization using the LIMA with PCI of non-LAD vessels. If both $\mathrm{LAD}$ and non-LAD territories are suitable for each respective procedure, patients can derive significant benefit from this combined approach. Three strategies for timing of hybrid revascularization exist, each with their own advantages and disadvantages. These include $\mathrm{CABG}$ followed by PCI, PCI followed by CABG, and simultaneous CABG and PCI in a hybrid suite. With a CABG-first approach, PCI may be performed during the index hospitalization or at a later date, depending on the clinical scenario. The most obvious advantage of this technique is the ability to perform CABG without the need for perioperative potent antiplatelet agents. Other advantages include the ability to verify LIMA patency at the time of PCI, and the opportunity to perform otherwise high-risk PCI knowing that left main or LAD bifurcation lesions are protected by a patent graft to the LAD. When considering a PCI-first approach, potential benefits include the ability to subsequently perform $\mathrm{CABG}$ in the event of suboptimal PCI results, and minimizing potential ischemia during minimally invasive $\mathrm{CABG}$ by revascularizing non-LAD targets. The tradeoff is the need for robust platelet inhibition at the time of CABG, although this can be minimized depending on the timing of surgery and the type of stent implanted. Finally, with the growing number of hospitals possessing hybrid suites, minimally invasive CABG can more readily be performed simultaneously with PCI in a combined procedure. This approach is attractive from both an economic and patient convenience vantage point. Clinical advantages include the ability to perform intraoperative angiography of the LIMA-LAD anastomosis 
and revision if necessary. Additionally, similar to the $\mathrm{CABG}$ first technique, it permits safe performance of otherwise high-risk PCI. The two primary disadvantages are increased perioperative bleeding risk, and the difficulty of coordinating cardiac catheterization and operative teams. Presently, there is no evidence overwhelmingly favoring any one approach. ${ }^{20}$ The clinician must decide on a treatment plan by carefully considering the individual patient's clinical and anatomic criteria along with the merits of each HCR strategy and the institution's resources.

While randomized trials and other high-level evidence for HCR are lacking, several publications have shown HCR to be safe and effective. Reports dating as early as 1996 have consistently reported low mortality rates, excellent graft patency, and acceptable rates of repeat revascularization in non-LAD territories. ${ }^{21-26}$ Some studies have shown advantages over conventional $\mathrm{CABG}$ with regard to ICU and hospital length of stay, perioperative blood loss, transfusion requirements, intubation time, and patient satisfaction. ${ }^{27,28} \mathrm{~A}$ recent metaanalysis by Harskamp et al, ${ }^{29}$ which included six studies and 1,190 patients, found that patients who underwent HCR had shorter hospital stays, required less blood transfusions, and returned to work earlier. While short-term results with HCR compare favorably to conventional CABG, long-term results are limited. In 2011, our group published results comparing 147 patients who underwent HCR with 588 matched patients who had undergone multivessel CABG. ${ }^{30}$ There was no perioperative death, stroke, or myocardial infarction among the HCR patients, and the overall incidence of major adverse cardiac and cerebrovascular events (MACCE) was similar between the HCR and off-pump coronary artery bypass (OPCAB) groups ( $0 \%$ vs $4.9 \%$ ). The transfusion rate was higher with OPCAB. At median follow-up of 3.2 years there was higher incidence of repeat revascularization with HCR (12.2\% vs 3.7\%, $P<0.0001)$; however, there was no difference in 5 -year survival $(83.4 \%$ vs $88.6 \%$ for OPCAB and HCR, respectively), and the vast majority of repeat interventions were on PCI-treated targets. We recently published our updated series of 300 patients who underwent HCR with continued excellent outcomes. ${ }^{13}$ A 2013 report suggested that higher risk patients with elevated SYNTAX scores (euroSCORE $>5$, SYNTAX $>33$ ) may have better outcomes with traditional $\mathrm{CABG} .{ }^{31}$ In this high-risk group, the incidence of MACCE at 30 days was $33 \%$ with HCR compared with $0 \%$ following $\mathrm{CABG}$. It is worth noting, however, that this was a small subset that included only 27 patients in the CABG group and nine in the HCR group, making it difficult to draw any conclusions. Another subset of patients who may be at higher risk of perioperative complications are those with isolated left main disease. When we compared our series of 27 patients who underwent HCR with 81 matched controls, we found no difference in MACCE between the two groups at a mean follow-up of 3.2 years. ${ }^{32}$ Compared with OPCAB, HCR was associated with a non-significant trend toward increased repeat revascularization $(7.4 \%$ vs $1.2 \%$, $P=0.09)$ and a significant decrease in perioperative transfusion requirements $(33.3 \%$ vs $61.7 \%, P=0.01)$.

Some have raised concern about the cost of robotic technology and HCR, and whether these approaches are sustainable in the current economic climate. Several authors have reported that despite initially higher costs, savings in postoperative expenses create a favorable cost effective analysis compared with OPCAB..$^{23,28,33}$ Kon et $\mathrm{al}^{28}$ and Poston et $\mathrm{al}^{33}$ found that reduced perioperative complications (decreased red blood cell transfusions and shorter ICU and hospital length of stay) led to cost savings in the postoperative period with HCR compared with OPCAB. This advantage was offset by higher intraoperative costs, with no significant overall cost difference. In the Poston et $\mathrm{al}^{33}$ study, when cost of the robot itself was amortized per patient, the robotic cases had significantly increased cost. In a recent publication by Halkos et al, ${ }^{34} \mathrm{HCR}$ yielded a greater contribution margin (best hospital pay estimate - total variable costs) than OPCAB. This analysis took into account the amortized cost of the da Vinci robot system as well as maintenance and disposables. With some studies also demonstrating earlier return to work, this should result in societal cost savings.

\section{Robotic mitral valve surgery}

Surgery for the mitral valve has evolved considerably over the last several decades. The largest shift has been with regard to the notion that in most cases valve repair is more beneficial than replacement. This philosophy was pioneered by Dr Alain Carpentier as "The French Correction" and has subsequently been championed by many surgeons. ${ }^{35}$ Since the advent of the Heartport (Cardiovastions; Edwards Lifesciences, Irvine, CA, USA) system in the 1990s, which allowed for reliable peripheral CPB cannulation and perfusion, there has been a growing trend toward minimally invasive sternal sparing techniques to treat isolated mitral valve disease. When compared with the sternotomy approach, these sternal sparing techniques may be advantageous with regard to hospital length of stay, cosmesis, and time until return to preoperative functional level. While the earliest non-sternotomy surgeries were performed via right anterior minithoracotomy with central cannulation, they subsequently evolved 
to a smaller incision mini-thoracotomy with peripheral cannulation and videoscopic assistance. ${ }^{36-38}$ These minimally invasive techniques have been shown to be safe, effective, and durable, even in the setting of redo operations and left ventricular dysfunction. ${ }^{39-41}$ Despite excellent results, there are unique challenges that arise with these techniques, including limited visualization of the subvalvular apparatus, the mandatory use of long-shafted instruments limiting dexterity, and anatomic variations such as small chest cavities or obesity that limit applicability to all patients, and may impact the type of valve repair that can be accomplished. These limitations prompted the industry and some surgeons to develop robot-assisted approaches, which improved visualization, dexterity, and applicability to a broader range of patients. The first reported case of robot-assisted intracardiac surgery with the da Vinci telemanipulator system was by Alain Carpentier's group in $1998 .^{2}$ They successfully repaired a large atrial septal defect and aneurysm. The following year Falk and colleagues reported results in their first ten patients undergoing robot-assisted mitral valve surgery. ${ }^{42}$ Although they had initial success in $90 \%$ of patients, they cautioned that surgery times are lengthier and the learning curve is long. Since that time, the robotic technology as well as surgical technique has evolved considerably, and more complex repairs can be accomplished reproducibly and in a timely manner. The surgery can now be accomplished with five $1-2 \mathrm{~cm}$ incisions in the right thorax, in addition to a femoral cutdown for venous and arterial cannulation.

In 2005, the results of a multicenter trial, which included 112 patients from ten centers led to FDA approval of the da Vinci telemanipulator system for mitral valve surgery. ${ }^{43}$ The following year, Murphy et $\mathrm{al}^{44}$ published their results in 127 patients using a totally endoscopic robot-assisted approach. Mitral valve repair was successfully accomplished in $94.2 \%$ of patients, and echocardiographic follow-up of 98 patients at a mean of 8.1 months revealed $96.9 \%$ freedom from greater than $1+$ mitral regurgitation (MR), and a $3.1 \%$ incidence of $2+\mathrm{MR}$. Since that time, a number of other high volume centers have reported their results with minimal rates of conversion to sternotomy, high repair rates, and excellent short-term outcomes. ${ }^{45-47}$ The largest of these series was by the Chitwood group and included 540 patients. ${ }^{45}$ Mihaljevic et $\mathrm{al}^{48}$ from the Cleveland Clinic published a large series comparing robotic mitral valve surgery to other approaches. They compared 261 posterior leaflet robotic mitral valve repairs to 114 repairs done by sternotomy, 114 by anterolateral mini-thoracotomy, and
270 by partial sternotomy. They found longer CPB and aortic cross-clamp times with the robotic approach, but similar quality of mitral repair, and similar rates of pulmonary, renal, and neurologic complications. The robotic group had less postoperative atrial fibrillation and an overall hospital length of stay that was approximately 1 day shorter than all other approaches. In 2010, Gammie et $\mathrm{al}^{49}$ reported results from the Society of Thoracic Surgeons database of over 28,000 mitral valve surgeries, including 4,322 "lessinvasive mitral valve surgeries." The report showed a high repair rate and lower transfusion requirements with the less-invasive approach, but raised concerns regarding an increased stroke risk compared with sternotomy (1.87\% vs $1.16 \%$, adjusted odds ratio $1.96,95 \%$ confidence interval 1.46-2.63). However, when comparing specifically the robotic approach to sternotomy, there was no difference in the incidence of perioperative stroke.

As with any surgical procedure, variations in technique exist between robotic mitral centers. One important variation is with regard to the aortic clamping and cardioplegia strategies, with centers using either a transthoracic clamp and a cardioplegia needle in the root, or the endoballoon system (Intraclude aortic occlusion device; Edwards Lifesciences). The endoballoon is typically advanced from the femoral artery to the aortic root, with aortic occlusion being accomplished by inflating the balloon and cardioplegia delivery through the lumen at the distal end of the endoballoon catheter. The previously mentioned study by Gammie et $\mathrm{al}^{49}$ found that, although the endoballoon was associated with an increase in perioperative stroke in non-robotic minimally invasive mitral valve surgery, this was not the case in patients undergoing robot-assisted surgery. A more recent study, from a center performing thoracoscopic mitral valve surgery, suggested that good results can be achieved using either aortic occlusion technique. ${ }^{50}$ Being facile with both may increase the applicability of the robotic technique to a larger proportion of patients.

A common theme among papers studying robotic mitral valve surgery is that the same repair techniques used in open surgery are being applied during robotic surgery. ${ }^{46,47,51}$ This is important when considering implementing this relatively new technology to address a pathology that has been successfully treated with good long-term results via median sternotomy. If the only difference is the approach to the mitral valve and not the repair itself, then the long-term repair results achieved with the sternotomy approach should be generalizable to the robotic mitral patient population. Although limited, there is some data on mid- and long-term results with robotic mitral 
valve surgery. Chitwood et $\mathrm{al}^{52}$ reported echocardiographic follow-up in 279 patients at a mean of 2.2 years with $92 \%$ freedom from greater than mild MR. Other studies have reported between $89 \%$ and $97 \%$ freedom from moderate or severe MR at 1 year. ${ }^{44,53}$ Although there is clearly a learning curve that must be overcome with this technique, these results are comparable to published results for open surgery.

\section{Concomitant procedures}

In the early experience with robotic mitral valve surgery, there were few, if any, concomitant procedures being performed. In the current era, with improvement in techniques and equipment, surgeons have been able to address comorbidities that frequently occur alongside mitral valve disease, such as atrial fibrillation, tricuspid valve disease, and interatrial communications. According to a recent systematic review by Seco et al, ${ }^{54}$ Maze procedures are performed in up $24 \%$ of cases, left atrial appendage occlusion in $12.5 \%$, and atrial septal defect and patent foramen ovale closure in $13 \%$. There are also many surgeons who now routinely close the left atrial appendage in all robotic mitral valve surgeries. Lewis et $\mathrm{al}^{55}$ recently published their series of 50 concomitant mitral and tricuspid valve repairs with excellent early outcomes. In general, any concomitant procedure appears to be well tolerated, while adding little, if any, morbidity.

\section{Quality of life and cost of robotic mitral valve surgery}

As with robotic coronary surgery, significant concern exists regarding the cost of robotic mitral valve surgery and its sustainability in the current economic health care climate. The cost disparity, if indeed one does exist, must be evaluated against the potential benefit, which in the case of robotic mitral valve repair likely relates to improved quality of life (QOL). Suri et al $^{56}$ compared QOL following robotic mitral valve surgery to sternotomy. They found a slight improvement with the robotic approach in the first postoperative year, and comparable QOL after 2 years. Unfortunately, at this time there is limited quantifiable QOL data comparing robotic to open mitral valve surgery, and the benefit must be inferred from shorter hospital stays and earlier return to work. It is clear that more studies on the subject are needed.

In comparison to QOL, there is more available data analyzing cost. In 2005, the group from Columbia University reviewed a group of 40 patients who underwent atrial septal defect or mitral valve repair using a robotic $(n=20)$ or sternotomy $(n=20)$ approach. ${ }^{57}$ When capital costs for the robot were excluded, total hospital cost was similar. However, when the analysis included amortized capital costs of the da Vinci system, robotic mitral valve surgery was associated with an increased cost of US\$3,444 per patient. Similarly, an Australian study showed no increase in cost when excluding the initial cost of the robot. ${ }^{58}$ The group from the Mayo clinic compared costs of robotic and open surgery before and after implementing systemic changes to their cardiac surgery care pathway. Interestingly, while robotic surgery at their institution was associated with increased cost prior to implementation of the changes, (US\$34,920 vs US\$32,650, $P<0.001)$, the cost difference disappeared after implementing protocols that improved efficiency in operating room management and standardized postoperative care (US\$30,606 vs US\$31,310, $P=0.876) .{ }^{59}$ Unlike the previously mentioned reports, this study included amortized costs of the robot in the analysis.

Overall, it would appear that robotic mitral valve procedures have a tendency to cost more than open surgery, particularly if capital costs are considered. However, if care teams focus on streamlining care, the difference can be minimized. Additionally, the morbid complication of deep sternal wound infection is eliminated with robotic mitral valve surgery. This has been reported to cost greater than US\$33,000 per patient, with an incidence of $0.27 \%-1.30 \%$ in mitral valve surgery done via sternotomy. ${ }^{60,61}$ Considering these comparisons, along with the potential QOL benefits, robotic mitral surgery appears to be a responsible and viable option. Furthermore, as with coronary surgery, additional savings are likely to be seen on a societal basis, with an earlier return to work compared with sternotomy.

\section{Atrial fibrillation ablation}

Both transcatheter and surgical treatments of atrial fibrillation are becoming increasingly popular. While the Cox-Maze procedure is most commonly performed concomitantly with mitral valve surgery, there are published reports describing isolated full Cox-Maze procedures performed with robotic assistance, with the energy source of choice generally being cryotherapy. In 2009, Rodriguez et $\mathrm{l}^{62}$ described their technique for stand-alone robotic atrial fibrillation surgery, and reported $88 \%$ freedom from atrial fibrillation at 6 months in 71 patients. As with most atrial fibrillation ablation procedures, the technique suffers from lack of rigorous long-term follow-up, but early results are promising.

\section{Epicardial lead placement}

Cardiac resynchronization therapy requires a pacing lead to be in contact with left ventricular muscle. This is most often accomplished by navigating a transvenous lead through the 
coronary sinus and into a coronary vein. This procedure is limited by the anatomy of the coronary venous system, making it technically challenging and in some cases not feasible. An alternative has been to place an epicardial lead via a left anterior minithoracotomy; however, some view this as a morbid procedure in patients with left ventricular dysfunction and other comorbidities. Robotic epicardial lead placement has been suggested as an alternative, and several authors report excellent immediate and long-term results with no complications. ${ }^{63-65}$ The largest published series included 78 patients with a mean follow-up of 44 months. This group reported $100 \%$ procedural success and stable pacing thresholds throughout follow-up. ${ }^{65}$

\section{Intracardiac mass resection}

While there have been a limited number of case reports and small case series describing robotic resection of left and right atrial tumors, this procedure is certainly being frequently performed in actual practice. ${ }^{66,67}$ One of the first reports was in 2005 by Murphy et $\mathrm{al}^{68}$ who described a series of three patients who underwent left atrial myxoma resection without any perioperative complications. Gao et $\mathrm{al}^{69}$ reported a series 19 consecutive patients, without any complications. Hassan and $\mathrm{Smith}^{70}$ published a case report describing robot-assisted excision of a left ventricle myxoma. We recently reviewed our center's experience in 69 patients, comparing robotic left atrial tumor resection $(n=30)$ with a conventional transsternal approach $(n=39) .{ }^{71}$ We found a trend toward shorter ICU and hospital length of stay, and fewer perioperative transfusions in the robotic group. There were no strokes in the robotic group, compared with two in the sternotomy group. The robotic technique is well suited for intracardiac tumor resection because it allows high definition visualization, favoring complete tumor resection and minimizing the chance of leaving behind residual tumor particles with embolization potential. Robotic excision of aortic valve papillary fibroelastoma has also been reported. ${ }^{44,72,73}$

\section{Other robotic procedures}

Case reports have been published describing technique for approaching various other cardiac pathologies robotically, including aortic valve replacement, ${ }^{74}$ apico-aortic conduit surgery, ${ }^{75}$ myotomy for myocardial bridging of the $\mathrm{LAD},{ }^{76}$ and right internal mammary to right coronary artery bypass for aberrant origin of the right coronary artery. ${ }^{77}$

\section{Congenital cardiac surgery}

Robotic assisted procedures have been performed in children; however, the technology is not as readily applicable as it is in adults. This is due to the smaller thoracic cavities and intercostal spaces, and limitations in peripheral cannulation. Suematsu et $\mathrm{al}^{78}$ reported nine successful robotic patent ductus arterious closures and six vascular ring repairs in 2005. The same year, Bacha et $\mathrm{al}^{79}$ described a robotic assisted repair of a sinus venosus defect in a 40-year-old male.

Robotic assisted repair of congenital defects, such as isolated atrial septal defects, are now routinely repaired in adults. Bonaros et $\mathrm{al}^{80}$ reported a series of 17 patients, ranging from 16 to 35 years of age, showing it to be safe and effective. At this time, the future of robotic assisted pediatric congenital cardiac surgery is uncertain due to the higher cost, lack of pediatric sized instruments, and smaller thoracic cavities in young children. On the other hand, robotic technology is well suited to approach a variety of adult congenital pathologies such as atrial septal defect, sinus venosus, and partial anomalous pulmonary venous return.

\section{The future}

Although slowly adopted initially, robotic cardiac surgical procedures are increasing in popularity. This trend has been fueled by advances in robotic technology, pioneering work by innovative surgeons, and increased demand by patients and cardiologists. Additionally, over the last 10 years, numerous publications have demonstrated the safety and potential advantages of robot-assisted surgery.

Robotics in CABG surgery has certainly evolved more slowly than in other surgical specialties. Some blame the absence of tactile feedback, but it also related to the meticulous nature of the surgery, which involves anastomosing 1-2 mm vessels on a potentially beating heart in a relatively fixed position within the thorax. Despite this limitation, pioneers in the field have made impressive strides, and the potential for progress is evident. With regard to robot-assisted mitral valve surgery, critics cite longer $\mathrm{CPB}$ times as a significant drawback of the procedure; however, these have not translated into increased perioperative morbidity, and in fact, patients tend to have shorter overall ICU and hospital stays.

While significant progress has been made, the da Vinci robot still has potential for improvement. A common belief is that the lack of haptic feedback severely limits its use in cardiac surgery; however, many surgeons that use it have found that the learning curve to adapt to visual cues is relatively short. Regardless, it is likely only a matter of time before haptic feedback is introduced. Other aspects of robotic technology will certainly evolve relatively quickly as well. Cameras will continue to get better, and instrument sizes will get smaller. Additionally, as with fluoroscopy, improvements in robotic 
software will allow three-dimensional echocardiography and computed tomography scan images to be overlaid onto the field, serving as a surgical blueprint.

Other robotics systems, some of which are not yet available for clinical use, are evolving alongside the da Vinci robot and are helping to shape the future of the field. Efforts are ongoing to produce new telemanipulation systems, including the DLR MiroSurge robotics system (German Aerospace Center, Oberpfaffenhofen-Wessling, Germany) and the SPORT Surgical System (Titan Medical, Toronto, ON, Canada). The Sensei X Robotic system (Hansen Medical Inc., Mountain View, CA, USA) is used for intracardiac navigation during cardiac ablation procedures. Snake-robotic technology, which allows telemanipulation of flexible arms that can more easily be maneuvered in a confined space, is also being developed and will aid intracorporeal surgery. Another area of research includes robotic cardiac stabilizers, which can compensate for residual cardiac motion during off-pump surgery. Going forward, we will likely see these related technologies being used together in order to vastly improve upon the current state of the art.

One elusive question is whether robotic cardiac surgical procedures will gain widespread acceptance and become routine for cardiac surgeons at large. Several limitations may prevent this from coming to fruition - most importantly, the necessity for a highly specialized team of surgeons, anesthesiologists, echocardiographers, and surgical assistants. Thankfully, centers interested in starting cardiac surgical robotic programs can benefit from the knowledge gained by experienced centers in order to mitigate the learning curve. These experienced centers have succeeded in decreasing the operative times and are now able to perform two or three robotic procedures in a day, resulting in a safer and more efficient operation that is more fiscally responsible. Given the exponential advances in robotic and general computer technology that we have witnessed over the last 20 years, it is impossible to predict what these machines will be capable of another 20 years from now. However, we are confident that robotics will be applicable to a wider variety of procedures and available to a larger number of surgeons, which will ultimately make its potential benefits accessible to a greater number of patients.

\section{Disclosure}

Drs Halkos and Murphy serve as consultants for Intuitive Surgical. The other authors report no conflicts of interest in this work.

\section{References}

1. Currie ME, Romsa J, Fox SA, et al. Long-term angiographic follow-up of robotic-assisted coronary artery revascularization. Ann Thorac Surg. 2012;93(5):1426-1431.

2. Carpentier A, Loulmet D, Aupècle B, et al. [Computer assisted open heart surgery. First case operated on with success]. C R Acad Sci III. 1998;321(5):437-442. French.

3. Loop FD, Lytle BW, Cosgrove DM, et al. Influence of the internalmammary-artery graft on 10-year survival and other cardiac events. N Engl J Med. 1986;314(1):1-6.

4. Loulmet D, Carpentier A, d'Attellis N, et al. Endoscopic coronary artery bypass grafting with the aid of robotic assisted instruments. J Thorac Cardiovasc Surg. 1999;118(1):4-10.

5. Argenziano M, Katz M, Bonatti J, et al. Results of the prospective multicenter trial of robotically assisted totally endoscopic coronary artery bypass grafting. Ann Thorac Surg. 2006;81(5):1666-1675.

6. Calafiore AM, Giammarco GD, Teodori G, et al. Left anterior descending coronary artery grafting via left anterior small thoracotomy without cardiopulmonary bypass. Ann Thorac Surg. 1996;61(6):1658-1663; discussion 1664-1665.

7. Mohr FW, Falk V, Diegeler A, et al. Computer-enhanced "robotic" cardiac surgery: experience in 148 patients. J Thorac Cardiovasc Surg. 2001;121(5):842-853.

8. Subramanian VA, McCabe JC, Geller CM. Minimally invasive direct coronary artery bypass grafting: two-year clinical experience. Ann Thorac Surg. 1997;64(6):1648-1653; discussion 1654-1655.

9. Gao C, Yang M, Wu Y, et al. Early and midterm results of totally endoscopic coronary artery bypass grafting on the beating heart. J Thorac Cardiovasc Surg. 2011;142(4):843-849.

10. Vassiliades TA Jr, Reddy VS, Puskas JD, Guyton RA. Long-term results of the endoscopic atraumatic coronary artery bypass. Ann Thorac Surg. 2007;83(3):979-985.

11. Halkos ME, Vassiliades TA, Myung RJ, et al. Sternotomy versus nonsternotomy LIMA-LAD grafting for single-vessel disease. Ann Thorac Surg. 2012;94(5):1469-1477.

12. Bonatti J, Schachner T, Bonaros N, et al. Technical challenges in totally endoscopic robotic coronary artery bypass grafting. J Thorac Cardiovasc Surg. 2006;131(1):146-153.

13. Halkos ME, Liberman HA, Devireddy C, et al. Early clinical and angiographic outcomes after robotic-assisted coronary artery bypass surgery. J Thorac Cardiovasc Surg. 2014;147(1):179-185.

14. Bonaros N, Schachner T, Wiedemann D, et al. Quality of life improvement after robotically assisted coronary artery bypass grafting. Cardiology. 2009;114(1):59-66.

15. Nesher N, Bakir I, Casselman F, et al. Robotically enhanced minimally invasive direct coronary artery bypass surgery: a winning strategy? J Cardiovasc Surg (Torino). 2007;48(3):333-338.

16. Bonaros N, Schachner T, Lehr E, et al. Five hundred cases of robotic totally endoscopic coronary artery bypass grafting: predictors of success and safety. Ann Thorac Surg. 2013;95(3):803-812.

17. Bonatti J, Lee JD, Bonaros N, Schachner T, Lehr EJ. Robotic totally endoscopic multivessel coronary artery bypass grafting: procedure development, challenges, results. Innovations (Phila). 2012;7(1):3-8.

18. Srivastava S, Barrera R, Quismundo S. One hundred sixty-four consecutive beating heart totally endoscopic coronary artery bypass cases without intraoperative conversion. Ann Thorac Surg. 2012;94(5): 1463-1468.

19. Wiedemann D, Bonaros N, Schachner T, et al. Surgical problems and complex procedures: issues for operative time in robotic totally endoscopic coronary artery bypass grafting. J Thorac Cardiovasc Surg. 2012;143(3):639-647. e2.

20. Srivastava MC, Vesely MR, Lee JD, et al. Robotically assisted hybrid coronary revascularization: does sequence of intervention matter? Innovations (Phila). 2013;8(3):177-183.

21. Angelini GD, Wilde P, Salerno TA, Bosco G, Calafiore AM. Integrated left small thoracotomy and angioplasty for multivessel coronary artery revascularisation. Lancet. 1996;347(9003):757-758. 
22. Cohen HA, Zenati M, Smith AJ, et al. Feasibility of combined percutaneous transluminal angioplasty and minimally invasive direct coronary artery bypass in patients with multivessel coronary artery disease. Circulation. 1998;98(11):1048-1050.

23. de Cannière D, Jansens JL, Goldschmidt-Clermont P, Barvais L, Decroly P, Stoupel E. Combination of minimally invasive coronary bypass and percutaneous transluminal coronary angioplasty in the treatment of double-vessel coronary disease: two-year follow-up of a new hybrid procedure compared with "on-pump" double bypass grafting Am Heart J. 2001;142(4):563-570.

24. Davidavicius G, Van Praet F, Mansour S, et al. Hybrid revascularization strategy: a pilot study on the association of robotically enhanced minimally invasive direct coronary artery bypass surgery and fractionalflow-reserve-guided percutaneous coronary intervention. Circulation. 2005;112(Suppl 9):I317-I322.

25. Kiaii B, McClure RS, Stewart P, et al. Simultaneous integrated coronary artery revascularization with long-term angiographic follow-up. J Thorac Cardiovasc Surg. 2008;136(3):702-708.

26. Gao C, Yang M, Wu Y, et al. Hybrid coronary revascularization by endoscopic robotic coronary artery bypass grafting on beating heart and stent placement. Ann Thorac Surg. 2009;87(3):737-741.

27. Reicher B, Poston RS, Mehra MR, et al. Simultaneous "hybrid" percutaneous coronary intervention and minimally invasive surgical bypass grafting: feasibility, safety, and clinical outcomes. Am Heart J 2008;155(4):661-667.

28. Kon ZN, Brown EN, Tran R, et al. Simultaneous hybrid coronary revascularization reduces postoperative morbidity compared with results from conventional off-pump coronary artery bypass. J Thorac Cardiovasc Surg. 2008;135(2):367-375.

29. Harskamp RE, Bagai A, Halkos ME, et al. Clinical outcomes after hybrid coronary revascularization versus coronary artery bypass surgery: a meta-analysis of 1,190 patients. Am Heart J. 2014;167(4):585-592.

30. Halkos ME, Vassiliades TA, Douglas JS, et al. Hybrid coronary revascularization versus off-pump coronary artery bypass grafting for the treatment of multivessel coronary artery disease. Ann Thorac Surg. 2011;92(5):1695-1701; discussion 1701-1702.

31. Leacche M, Byrne JG, Solenkova NS, et al. Comparison of 30-day outcomes of coronary artery bypass grafting surgery versus hybrid coronary revascularization stratified by SYNTAX and euroSCORE. J Thorac Cardiovasc Surg. 2013;145(4):1004-1012.

32. Halkos ME, Rab ST, Vassiliades TA, et al. Hybrid coronary revascularization versus off- pump coronary artery bypass for the treatment of left main coronary stenosis. Ann Thorac Surg. 2011;92(6):2155-2160.

33. Poston RS, Tran R, Collins M, et al. Comparison of economic and patient outcomes with minimally invasive versus traditional off-pump coronary artery bypass grafting techniques. Trans Meet Am Surg Assoc Am Surg Assoc. 2008;126:281-289.

34. Halkos ME, Ford L, Peterson D, et al. The impact of hybrid coronary revascularization on hospital costs and reimbursements. Ann Thorac Surg. 2014;97(5):1610-1615; discussion 1615-1616.

35. Carpentier A. Cardiac valve surgery - the "French correction". JThorac Cardiovasc Surg. 1983;86(3):323-337.

36. Navia JL, Cosgrove DM. Minimally invasive mitral valve operations. Ann Thorac Surg. 1996;62(5):1542-1544.

37. Carpentier A, Loulmet D, Carpentier A, et al. [Open heart operation under videosurgery and minithoracotomy. First case (mitral valvuloplasty) operated with success]. C R Acad Sci III. 1996;319(3):219-223. French

38. Chitwood WR, Wixon CL, Elbeery JR, Moran JF, Chapman WH, Lust RM. Video-assisted minimally invasive mitral valve surgery. J Thorac Cardiovasc Surg. 1997;114(5):773-780; discussion 780-782.

39. McClure RS, Cohn LH, Wiegerinck E, et al. Early and late outcomes in minimally invasive mitral valve repair: an eleven-year experience in 707 patients. J Thorac Cardiovasc Surg. 2009;137(1):70-75.

40. Atluri P, Woo YJ, Goldstone AB, et al. Minimally invasive mitral valve surgery can be performed with optimal outcomes in the presence of left ventricular dysfunction. Ann Thorac Surg. 2013;96(5):1596-1601; discussion 1601-1602.
41. Arcidi JM, Rodriguez E, Elbeery JR, Nifong LW, Efird JT, Chitwood WR. Fifteen-year experience with minimally invasive approach for reoperations involving the mitral valve. J Thorac Cardiovasc Surg. 2012;143(5):1062-1068.

42. Falk V, Autschbach R, Krakor R, et al. Computer-enhanced mitral valve surgery: toward a total endoscopic procedure. Semin Thorac Cardiovasc Surg. 1999;11(3):244-249.

43. Nifong LW, Chitwood WR, Pappas PS, et al. Robotic mitral valve surgery: a United States multicenter trial. J Thorac Cardiovasc Surg. 2005;129(6):1395-1404.

44. Murphy DA, Miller JS, Langford DA, Snyder AB. Endoscopic robotic mitral valve surgery. J Thorac Cardiovasc Surg. 2006;132(4):776-781.

45. Nifong LW, Rodriguez E, Chitwood WR. 540 consecutive robotic mitral valve repairs including concomitant atrial fibrillation cryoablation. Ann Thorac Surg. 2012;94(1):38-42; discussion 43.

46. Suri RM, Burkhart HM, Daly RC, et al. Robotic mitral valve repair for all prolapse subsets using techniques identical to open valvuloplasty: establishing the benchmark against which percutaneous interventions should be judged. J Thorac Cardiovasc Surg. 2011;142(5):970-979.

47. Mihaljevic T, Pattakos G, Gillinov AM, et al. Robotic posterior mitral leaflet repair: neochordal versus resectional techniques. Ann Thorac Surg. 2013;95(3):787-794.

48. Mihaljevic T, Jarrett CM, Gillinov AM, et al. Robotic repair of posterior mitral valve prolapse versus conventional approaches: potential realized. J Thorac Cardiovasc Surg. 2011;141(1):72-80. e1-e4.

49. Gammie JS, Zhao Y, Peterson ED, O’Brien SM, Rankin JS, Griffith BP. J Maxwell Chamberlain Memorial Paper for adult cardiac surgery. Lessinvasive mitral valve operations: trends and outcomes from the Society of Thoracic Surgeons Adult Cardiac Surgery Database. Ann Thorac Surg. 2010;90(5):1401-1408, 1410. e1; discussion 1408-1410.

50. Mazine A, Pellerin M, Lebon J-S, Dionne P-O, Jeanmart H, Bouchard D. Minimally invasive mitral valve surgery: influence of aortic clamping technique on early outcomes. Ann Thorac Surg. 2013;96(6):2116-2122.

51. Rodriguez E, Nifong LW, Chu MWA, Wood W, Vos PW, Chitwood WR Robotic mitral valve repair for anterior leaflet and bileaflet prolapse. Ann Thorac Surg. 2008;85(2):438-444.

52. ChitwoodWR, Jr RodriguezE, Chu MWA, Hassan A, Ferguson TB, Vos PW, Nifong LW. Robotic mitral valve repairs in 300 patients: A single-center experience. J Thor Cardiovasc Surg. 2008;136(2):436- 441.

53. Ramzy D, Trento A, Cheng W, et al. Three hundred robotic-assisted mitral valve repairs: the Cedars-Sinai experience. J Thorac Cardiovasc Surg. 2014;147(1):228-235.

54. Seco M, Cao C, Modi P, et al. Systematic review of robotic minimally invasive mitral valve surgery. Ann Cardiothorac Surg. 2013;2(6): 704-716.

55. Lewis CTP, Stephens RL, Tyndal CM, Cline JL. Concomitant robotic mitral and tricuspid valve repair: technique and early experience. Ann Thorac Surg. 2014;97(3):782-787.

56. Suri RM, Antiel RM, Burkhart HM, et al. Quality of life after early mitral valve repair using conventional and robotic approaches. Ann Thorac Surg. 2012;93(3):761-769.

57. Morgan JA, Thornton BA, Peacock JC, et al. Does robotic technology make minimally invasive cardiac surgery too expensive? A hospital cost analysis of robotic and conventional techniques. J Card Surg. 2005;20(3):246-251.

58. Kam JK, Cooray SD, Kam JK, Smith JA, Almeida AA. A cost-analysis study of robotic versus conventional mitral valve repair. Heart Lung Circ. 2010;19(7):413-418.

59. Suri RM, Thompson JE, Burkhart HM, et al. Improving affordability through innovation in the surgical treatment of mitral valve disease. Mayo Clin Proc. 2013;88(10):1075-1084.

60. LaPar DJ, Crosby IK, Rich JB, et al. A contemporary cost analysis of postoperative morbidity after coronary artery bypass grafting with and without concomitant aortic valve replacement to improve patient quality and cost-effective care. Ann Thor Surg. 2013;96(5):1621-1627. 
61. Cheng DCH, Martin J, Lal A, et al. Minimally invasive versus conventional open mitral valve surgery: a meta-analysis and systematic review. Innovations. 2011;6(2):84-103.

62. Rodriguez E, Cook RC, Chu MWA, Chitwood WR Jr. Minimally invasive bi-atrial cryomaze operation for atrial fibrillation. Oper Tech Thorac Cardiovasc Surg. 2009;14(3):208-223.

63. Navia JL, Atik FA, Grimm RA, et al. Minimally invasive left ventricular epicardial lead placement: surgical techniques for heart failure resynchronization therapy. Ann Thorac Surg. 2005;79(5):1536-1544.

64. Derose JJ Jr, Belsley S, Swistel DG, Shaw R, Ashton RC Jr. Robotically assisted left ventricular epicardial lead implantation for biventricular pacing: the posterior approach. Ann Thorac Surg. 2004;77(4):1472-1474.

65. Kamath GS, Balaram S, Choi A, et al. Long-term outcome of leads and patients following robotic epicardial left ventricular lead placement for cardiac resynchronization therapy. Pacing Clin Electrophysiol. 2011;34(2):235-240.

66. Gutiérrez de Loma J, Valderrama Marcos JF, Melero Tejedor JM, González González S. Left atrial myxoma: extraction by robotic and vacuum assistance. Innovations (Phila). 2009;4(6):351-353.

67. Schilling J, Engel AM, Hassan M, Smith JM. Robotic Excision of atrial myxoma. J Card Surg. 2012;27(4):423-426.

68. Murphy DA, Miller JS, Langford DA. Robot-assisted endoscopic excision of left atrial myxomas. J Thorac Cardiovasc Surg. 2005;130(2):596-597.

69. Gao C, Yang M, Wang G, et al. Excision of atrial myxoma using robotic technology. J Thorac Cardiovasc Surg. 2010;139(5):1282-1285.

70. Hassan M, Smith JM. Robotic assisted excision of a left ventricular myxoma. Interact Cardiovasc Thorac Surg. 2012;14(1):113-114.

71. Moss E, Halkos ME, Miller JS, Kilgo P, Murphy DA. Comparison of endoscopic robotic versus sternotomy approach for the resection of left atrial tumors. Abstract presented at ISMICS 2014.
72. Murphy ET. Robotic excision of aortic valve papillary fibroelastoma and concomitant maze procedure. Glob Cardiol Sci Pract. 2013;2012(2): 93-100.

73. Woo YJ, Grand TJ, Weiss SJ. Robotic resection of an aortic valve papillary fibroelastoma. Ann Thorac Surg. 2005;80(3):1100-1102.

74. Folliguet TA, Vanhuyse F, Konstantinos Z, Laborde F. Early experience with robotic aortic valve replacement. Eur J Cardiothorac Surg. 2005;28(1):172-173.

75. Gammie JS, Lehr EJ, Griffith BP, Dawood MY, Bonatti J. Roboticassisted aortic valve bypass (apicoaortic conduit) for aortic stenosis. Ann Thorac Surg. 2011;92(2):726-728.

76. Alima MB, Eynden FV, Preumont N, Jansens JL. Robotic-assisted surgical myotomy in a 27-year-old man with myocardial bridging of the left anterior descending coronary artery. Interact Cardiovasc Thorac Surg. 2010;11(2):185-187.

77. Chen K-CJ, Teefy P, Kiaii B, Vezina WC, Chu MW. Robotic coronary artery bypass for aberrant right coronary artery stenosis. Can J Cardiol. 2010;26(8):326-327.

78. Suematsu Y, Mora BN, Mihaljevic T, del Nido PJ. Totally endoscopic robotic-assisted repair of patent ductus arteriosus and vascular ring in children. Ann Thorac Surg. 2005;80(6):2309-2313.

79. Bacha EA, Bolotin G, Consilio K, Raman J, Ruschhaupt DG. Robotically assisted repair of sinus venosus defect. J Thorac Cardiovasc Surg. 2005;129(2):442-443.

80. Bonaros N, Schachner T, Oehlinger A, et al. Robotically assisted totally endoscopic atrial septal defect repair: insights from operative times, learning curves, and clinical outcome. Ann Thorac Surg. 2006;82(2):687-693.
Robotic Surgery: Research and Reviews

\section{Publish your work in this journal}

Robotic Surgery: Research and Reviews is an international, peer reviewed, open access, online journal publishing original research, commentaries, reports, and reviews on the theory, use and application of robotics in surgical interventions. Articles on the use of supervisory-controlled robotic systems, telesurgical devices, and shared-control systems are

\section{Dovepress}

invited. The manuscript management system is completely online and includes a very quick and fair peer review system, which is all easy to use. Visit http://www.dovepress.com/testimonials.php to read real quotes from published authors. 